\title{
Ocular myasthenia : evaluation of Tensilon tonography and electronystagmography as diagnostic tests
}

\author{
M. J. CAMPBELL, E. SIMPSON, A. L. CROMBIE, AND J. N. WALTON \\ From the Department of Neurology, Regional Neurological Centre, The General Hospital, \\ and the Department of Ophthalmology, Royal Victoria Infirmary, Newcastle upon Tyne
}

SUMMARY The value of electronystagmography (ENG) and of tonography in monitoring the beneficial effect of edrophonium chloride (Tensilon) on the extraocular muscles in myasthenia gravis has been assessed. Studies were performed on 17 patients with myasthenia gravis and on 18 control subjects, of whom nine had extraocular muscle weakness due to myopathic or neurogenic lesions.

Electronystagmography recorded the repetitive following movements of the eyes elicited during optokinetic nystagmus. Neuromuscular fatigue with the subsequent beneficial response to Tensilon was clearly seen in $50 \%$ of patients with myasthenia. False positive responses were not seen in control subjects but in many of these, as in the remaining myasthenic patients, the amplitude and rate of nystagmus seen in the ENG was very variable. These difficulties suggest that the ENG is of limited value as a diagnostic test in myasthenia gravis.

Tonography, recording the intraocular pressure of the eye continuously over four minutes, was found to be of considerable value. We found that the intraocular pressure fell on average by 1.6 to $1.8 \mathrm{~mm} \mathrm{Hg}$ over a one minute period in the control recordings but increased by a mean of $1.6 \mathrm{~mm}$ $\mathrm{Hg}$ in patients with myasthenia, with a peak effect 35 seconds after Tensilon. In only one patient was there a complete failure of response. This patient, and also another woman who showed a less striking response, had severe myasthenia with a fixed ocular weakness. It is suggested that an absence of any increase in tension with Tensilon may be seen in patients with permanent neostigmineresistant myopathic change. A small false positive response was seen on one occasion only in a patient with a sympathetic nerve lesion.

Tensilon tonography, as a simple painless procedure, would appear to be of considerable value in the diagnosis of ocular myasthenia and also as a diagnostic test in the exclusion of myasthenia as a cause of isolated extraocular neuromuscular weakness.

During the course of the management of patients with myasthenia gravis we became aware of the problems which arise in the diagnosis and treatment of patients in whom the neuromuscular defect is clinically confined to the extraocular muscles. The response to edrophonium chloride (Tensilon) (Osserman and Kaplan, 1952) may be difficult to evaluate clinically, especially when extraocular paresis is unaccompanied by ptosis. While in some patients the response to anticholinesterase agents may be dramatic, in others, and especially in those with prolonged weakness, little or incomplete benefit may occur. Electromyography of skeletal muscles during repetitive nerve stimulation may not demonstrate the typical neuromuscular fatigue in some patients, in whom the clinical features are confined to the extraocular muscles. Electromyography of the extraocular muscles is uncomfortable and may be difficult to evaluate, while tetanic stimulation of the orbicularis oculi muscles is painful.

Recently two objective tests of value in the diagnosis of myasthenia gravis have been described, utilizing the response of the extraocular muscles to Tensilon. Blomberg and Persson (1965) studied the 
following movements of the eyes which occur in induced optokinetic nystagmus, using electronystagmography, and Glaser, Miller, and Gass (1966) reported the effect on intraocular pressure as measured by tonography. The purpose of this study was to evaluate further these tests in the diagnosis of ocular myasthenia.

\section{MATERIAL AND METHODS}

Seventeen patients with proven myasthenia gravis were studied (Table 1). In seven patients the studies were performed during the original investigation of their weakness and before treatment with anticholinesterase agents was commenced. In the remaining patients the studies were performed during periods of clinical weakness. In the latter cases the cooperation of the patients was obtained to omit medication in some instances and in others the tests were performed just before the patient took regular medication. In only two patients (N.Co. and L.S.) were the studies performed less than four hours after receiving anticholinesterase therapy with Prostigmin and/or Mestinon. Both of these patients had severe disease with bulbar and ocular involvement and at the time of study were showing evidence of distress. Electronystagmography (ENG) was performed on 12 patients and tonography was recorded on 16 occasions in 14 patients.

TABLE 1

PATIENTS STUDIED WITH MYASTHENIA GRAVIS

\begin{tabular}{lcclc}
\hline Patient & Sex & $\begin{array}{c}\text { Age } \\
(y r)\end{array}$ & \multicolumn{1}{c}{ Muscle weakness } & Tests \\
\hline 1 J.A. & M & 38 & Generalized with extraocular & NT \\
2 N. Cam. & M & 33 & Generalized with extraocular & T \\
3 N. Co. & F & 37 & Generalized with \\
4 G.C. & F & 7 & Extraocular with ptosis & N \\
5 W.H. & M & 64 & Extraocular with ptosis & NT \\
6 E.A.K. & M & 30 & Generalized with extraocular & T \\
7 E.L. & F & 55 & Generalized with extraocular & T \\
8 C. McG. & M & 70 & Generalized with extraocular & NT \\
9 W.P. & M & 64 & Extraocular with ptosis & NT \\
10 L.S. & F & 45 & Generalized with extraocular & NT \\
11 L.T. & M & 36 & Extraocular with ptosis & N \\
12 H.T. & M & 56 & Generalized & NT \\
13 J.T. & M & 41 & Extraocular only & NT \\
14 B.Wat. & F & 30 & Extraocular only & T \\
15 C.W. & M & 15 & Generalized with extraocular & NT \\
16 B. Wev. & M & 76 & Generalized only & NT \\
17 J.W. & M & 62 & Ext raocular only & N \\
\hline
\end{tabular}

$\mathrm{N}=$ Nystagmography in 12 patients. $\mathrm{T}=$ Tonography in 14 patients

Eighteen control patients were studied similarly (Table 2). Extraocular muscle weakness due to a myopathic process (ocular myopathy) was present in four patients, while muscle weakness due to a lesion of a single third or sixth cranial nerve was present in a further five cases. Four other patients had miscellaneous mild illnesses without extraocular muscle involvement and five healthy young adults acted as volunteers. Electronystagmography was performed on 11 and tonography on 10 of the control patients.
TABLE 2

THE 18 CONTROL PATIENTS STUDIED

\begin{tabular}{|c|c|c|c|c|}
\hline Patient & $\operatorname{Sex}$ & $\begin{array}{l}\text { Age } \\
(y r)\end{array}$ & Diagnosis & Tests \\
\hline 18 R.B. & $\mathbf{M}$ & 53 & $\begin{array}{l}\text { Myotonic dystrophy with } \\
\text { extraocular weakness }\end{array}$ & NT \\
\hline 19 J.D. & $\mathbf{M}$ & 53 & Oculopharyngeal myopathy & $\mathrm{T}$ \\
\hline 20 E.J. & $\mathbf{F}$ & 46 & $\begin{array}{l}\text { Thyrotoxic myopathy with } \\
\text { extraocular weakness; myo- } \\
\text { tonic pupils }\end{array}$ & $\mathrm{T}$ \\
\hline 21 D. McM. & $\mathbf{M}$ & 31 & Ocular myopathy & $\mathrm{T}$ \\
\hline 22 R.H. & $\mathbf{M}$ & 33 & Left oculomotor paresis & $T$ \\
\hline 23 A.H. & $\mathbf{M}$ & 20 & Left abducens palsy & $\mathbf{T}$ \\
\hline 24 D.K. & $\mathbf{M}$ & 21 & Left abducens palsy & $\mathbf{N}$ \\
\hline 25 E.O. & $\mathbf{F}$ & 20 & Bilateral abducens paresis & $\mathbf{N}$ \\
\hline 26 M.W. & $\mathbf{F}$ & 31 & Left abducens paresis & $\mathbf{N}$ \\
\hline 27 R.S. & $\mathbf{M}$ & 37 & Left Horner's syndrome & $\mathbf{T}$ \\
\hline 28 N.C. & $\mathrm{F}$ & 41 & Anxiety state & $\mathbf{N}$ \\
\hline 29 C.S. & $\mathrm{F}$ & 46 & Anxiety state & NT \\
\hline 30 N.S. & $\mathbf{M}$ & 65 & See-saw nystagmus & $\mathbf{N}$ \\
\hline 31 M.A. & $\mathbf{F}$ & 21 & Normal & $\mathbf{N}$ \\
\hline 32 M.C. & $\mathbf{M}$ & 32 & Normal & NT \\
\hline 33 L.H. & $\mathbf{M}$ & 21 & Normal & $\mathbf{T}$ \\
\hline 34 Y.H. & $\mathbf{F}$ & 21 & Normal & $\mathbf{N}$ \\
\hline 35 L.M. & $\mathbf{F}$ & 19 & Normal & $\mathbf{N}$ \\
\hline
\end{tabular}

$\mathrm{N}=$ Nystagmography. $\mathrm{T}=$ Tonography.

ELECTRONYSTAGMOGRAPHY (ENG) utilizes the corneo retinal potential. In man the cornea is positively chargedb and the retina negatively charged and hence the eye functions as a rotating dipole. With recording electrodes at the outer canthus of both eyes, deviation of gaze causes a change in electrical potential at these sites (Schotto 1922), which is almost linearly related to the arc of deviation (Aschan, Bergstedt, and Stahle, 1956).

Optokinetic nystagmus was induced with a 12 in. $(30 \mathrm{~cm})$ striped drum situated at $30 \mathrm{~cm}$ distance rotating with a speed of 48 to 60 revolutions/minute (or 270 to $360 \%$ second angular velocity), and 144 to 180 frames/ minute. Nystagmus of both eyes was recorded simultaneously from skin electrodes placed at the outer canthus of both eyes, over the nasion, and with a reference electrode on one forehead laterally. We employed a direct-current pre-amplifier (Offner) with a time constant of $0.3 \mathrm{sec}$ and utilized two writing channels at a slow paper speed of 1.5 or $3 \mathrm{~cm} / \mathrm{second}$. Initial control recordings of 30 second runs were made with the drum revolving first clockwise and then in reverse-that is, with the optokinetic nystagmus (fast component) to the right and later to the left. Edrophonium chloride (Tensilon) $10 \mathrm{mg}$ was then injected intravenously over five to 10 seconds and the recordings were repeated after one, three, and five minutes.

TONOGRAPHY Intraocular pressure was recorded with an electronic Schiotz tonometer linked to a continuous recorder (Schwarzer). The intraocular pressures were recorded in the standard manner over a four-minute period. At one minute $1 \mathrm{ml}$. normal saline was injected intravenously through an indwelling brachial needle, as 
a control. The pressures were then recorded from the second eye and Tensilon $10 \mathrm{mg}$. was injected intravenously over a five to 10 second interval at one minute. The records were calibrated before and after the recordings and the intraocular pressure was calculated (after Friedenwald, 1955).

\section{RESULTS}

ELECTRONYSTAGMOGRAPHY Neuromuscular fatigue of the extraocular muscles, as in myasthenia, may readily be demonstrated by ENG recording of optokinetic nystagmus. At a suitable rate of stimulus the amplitude of successive beats of nystagmus decreases, beats are progressively omitted and the record becomes flat. Considerable variation in response may be seen between the two eyes and also according to the direction of the nystagmus. These findings are illustrated in Fig. 1 which demonstrates the lower amplitude response, and hence the smaller deviation of gaze, elicited in the control recording from the left eye. In the right eye greater weakness and fatiguability appeared to be present in the recording with the drum rotating anticlockwise, that is, in the medial rather than the lateral rectus muscle. The considerable benefit afforded by anticholinesterase therapy with Tensilon is also seen. A much greater response appears to be present in the weaker left eye, but the frequency and amplitude of the beats in the right eye is also better maintained than previously. In general the beneficial response to Tensilon usually waned by three minutes and disappeared completely after five minutes, as is seen in Fig. 2.

Electronystagmography was performed on 12 patients with proven myasthenia gravis: in six cases neuromuscular fatigue of the extraocular muscles was seen and a beneficial response to Tensilon was clearly demonstrated; in three patients (J.A., C.McG., and J.T.) all of whom had ocular weakness, a considerable variation in the amplitude and regularity of the nystagmus was recorded initially and the response to Tensilon was equivocal; in the remainder there was no objective evidence of neuromuscular fatigue in two patients (H.T. and L.T.), and severe weakness was evident in one (L.S.) with minimal fatigue but without a clear response to Tensilon. This last woman had received anticholinesterase therapy (Mestinon) four hours previously but was showing evidence of bulbar weakness at the time of the recording.

It proved impossible to quantitate the ENG recordings either on the rate or amplitude of the nystagmus. In normal subjects there is an optimum drum speed at which optokinetic nystagmus is regularly induced with the most constant amplitude of response. We found that this required considerable concentration and cooperation, and that empirically 144 to 180 beats/minute were most satisfactory. However, even with the most ideal, healthy subject the amplitude of response-that is, the angular

L'

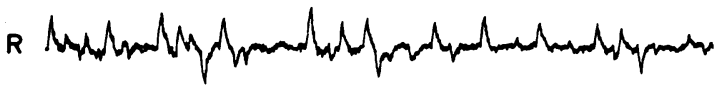

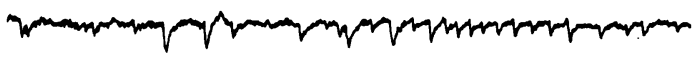
CLOCKWISE TO LEFT — CONTROL — ANTICLOCKWISE TO RIGHT W.P. 0 64
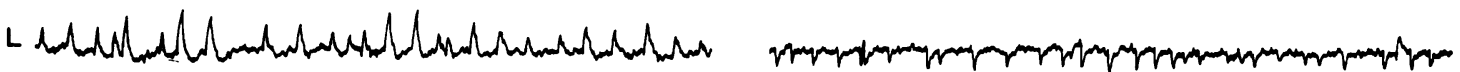

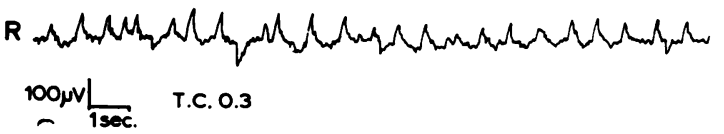

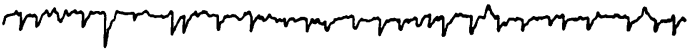
T.C. 0.3

FIG. 1. Record of electronystagmography in a myasthenic patient. Top record shows optokinetic nystagmus and bottom record shows increased amplitude after injection of Tensilon. 

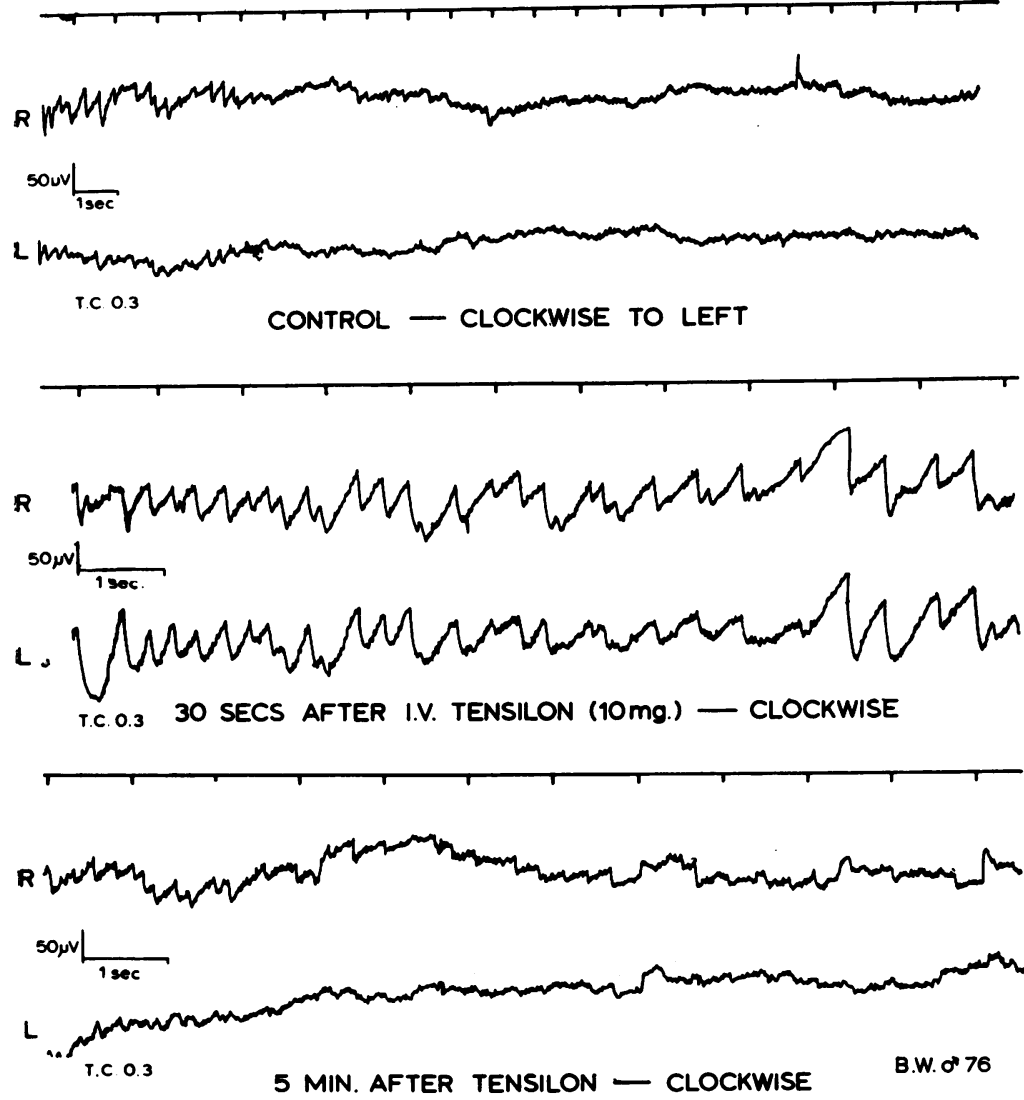

FIG. 2. Record of electronystagmography in a myasthenic patient. Top record shows optokinetic nystagmus, middle record shows increased amplitude after Tensilon and bottom record shows decrease in Tensilon response after five minutes. deviation of the eyes-may vary considerably from beat to beat. Certain subjects, both normal and myasthenic, showed a phenomenon of habituation in which the amplitude of successive beats became smaller in anticipation of the next stimulus. Hence apparent neuromuscular fatigue may be observed in normal healthy subjects but no false positive responses to Tensilon were obtained in the control subjects.

TONOGRAPHY A typical record of intraocular pressure as measured in this study is shown in Fig. 3. In the control recording from the right eye a steady non-linear decline in intraocular pressure is seen over four minutes and no discernible effect of the injection of normal saline is seen. The intraocular pressure was calculated to have fallen by $1.8 \mathrm{~mm} \mathrm{Hg}$ over the 60 seconds period after the injection. After Tensilon the intraocular pressure in the left eye rose steadily by $3.1 \mathrm{~mm} \mathrm{Hg}$, being maximal 40 seconds after the injection. The increase in intraocular pressure rapidly fell within one minute.
The results of the tonographic studies in 14 patients with myasthenia gravis and 10 control subjects are shown in Table 3 . The mean fall in intraocular pressure over the second minute and within one minute of receiving the control injection of normal saline solution was $1.6 \pm 0.31 \mathrm{~mm} \mathrm{Hg}$ in the myasthenic patients and $1.8 \pm 0.30 \mathrm{~mm} \mathrm{Hg}$ in the controls. Only a single anomalous control record, in a myasthenic patient (J.T.), was obtained and is shown in Fig. 4. A similar mean fall in tension of $1.6 \pm 0.36 \mathrm{~mm} \mathrm{Hg}$ was recorded in the control subjects following Tensilon. One surprising finding was a rise in tension of $0.8 \mathrm{~mm} \mathrm{Hg}$ maximal at 120 seconds after Tensilon, in an eye with a sympathetic nerve palsy thought to be due to migraine. In the 14 myasthenic patients studied, the mean intraocular tension rose after Tensilon by $1.6 \pm 0.7 \mathrm{~mm} \mathrm{Hg}$ with the peak effect at approximately 35 seconds. Applying Student's $t$ test to the above figures showed that there was no significant difference in response in the control group of patients between the right and left eyes irrespective of whether saline or Tensilon 

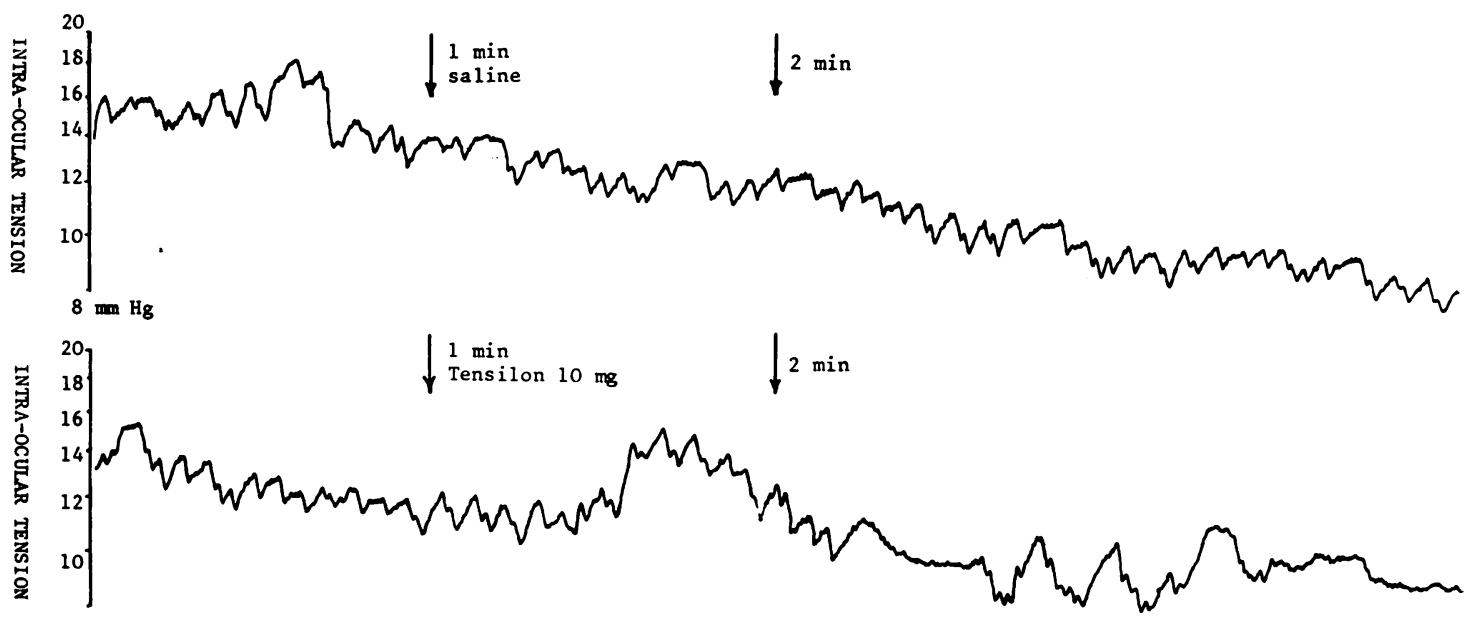

$8 \mathrm{~mm} \mathrm{Hg}$

BW $\quad \sigma^{\circ} 76$

FIG. 3. Record of Tensilon tonography in a myasthenic patient. Top record shows intraocular pressure tracing and the first arrow indicates injection of saline. Bottom record shows intraocular pressure tracing and the first arrow indicates injection of Tensilon.

TABLE 3

STUDIES OF TONOGRAPHY IN PATIENTS WITH MYASTHENIA GRAVIS AND CONTROLS

\begin{tabular}{|c|c|c|c|}
\hline \multirow[t]{2}{*}{ Patient } & \multicolumn{2}{|c|}{ Intraocular pressure $(\mathrm{mm} \mathrm{Hg})$} & \multirow{2}{*}{$\begin{array}{l}\text { Peak effect } \\
(\mathrm{sec})\end{array}$} \\
\hline & Within 1 min of $N$ saline & Within 1 min of Tensilon & \\
\hline \multicolumn{4}{|c|}{ Myasthenic patients } \\
\hline 1 J.A. & & $12.4 \rightleftharpoons 14.3=+1.9$ & 20 \\
\hline 2 N.Cam. & & $12 \cdot 4 \rightleftharpoons 14 \cdot 7=+2 \cdot 3$ & 55 \\
\hline 3 N.Co. & & $12.4 \rightleftharpoons 10.0=-2.4$ & - \\
\hline 5 W.H. & $14.6-12.9=-1.7$ & $12 \cdot 7 \rightleftharpoons 15 \cdot 5=+2 \cdot 8$ & 50 \\
\hline 6 E.A.K. & & $13.0 \rightleftharpoons 15.4=+2.4$ & 45 \\
\hline 7 E.L. & & $13.2 \rightleftharpoons 13.8=+0.6$ & 30 \\
\hline 8 C.McG. & $14 \cdot 1-11 \cdot 0=-3 \cdot 1$ (OD) & $13.6 \rightleftharpoons 14.6=+1.0(\mathrm{OS})$ & 20 \\
\hline & $8.7-6.6=-2.1(\mathrm{OD})$ & $9 \cdot 2 \rightleftharpoons 10.5=+1.3(\mathrm{OS})$ & 25 \\
\hline 9 W.P. & $14.6-13.4=-1.2(\mathrm{OS})$ & $20 \cdot 1 \rightleftharpoons 20 \cdot 0=-0.1$ (OD) & 20 \\
\hline & & $18.7 \rightleftharpoons 20.8=+2.1(\mathrm{OS})$ & 30 \\
\hline 10 L.S. & $16 \cdot 7-14.5=-2.2$ & $14 \cdot 1 \rightleftharpoons 14 \cdot 1=0$ & 45 \\
\hline 12 H.T. & & $12.4 \rightleftharpoons 13.0=+0.6$ & 20 \\
\hline 13 J.T. & $10 \cdot 1-11 \cdot 2=+1 \cdot 1(1 \min ?)$ & $9 \cdot 5 \rightleftharpoons 14 \cdot 5=+5.0$ & 20 \\
\hline 14 B.Wat. & $14.1-12.2=-1.9$ & $15 \cdot 6 \rightleftharpoons 17 \cdot 3=+1.7$ & 35 \\
\hline 15 C.W. & $14.2-12.7=-1.5$ & $11.9 \rightleftharpoons 14.6=+2.7$ & 50 \\
\hline 16 B.Wev. & $14 \cdot 3-12 \cdot 5=-1 \cdot 8$ & $11 \cdot 9 \rightleftharpoons 15 \cdot 0=+3 \cdot 1$ & 40 \\
\hline & & r & \\
\hline $\begin{array}{l}\text { Control patients } \\
18 \text { R.B. }\end{array}$ & $14 \cdot 0-11 \cdot 0=-3.0$ & $13 \cdot 4 \rightleftharpoons 10 \cdot 2=-3 \cdot 2$ & \\
\hline 19 J.D. & $18 \cdot 1-17 \cdot 1=-1.0$ & $14 \cdot 1 \rightleftharpoons 12.6=-1.5$ & \\
\hline 20 E.J. & $18 \cdot 8-17 \cdot 1=-1 \cdot 7(\mathrm{OD})$ & $19 \cdot 1 \rightleftharpoons 17 \cdot 1=-2 \cdot 0(\mathrm{OS})$ & \\
\hline & $14.0-12.4=-1.6(O D)$ & $16.1 \rightleftharpoons 14.5=-1.6(\mathrm{OS})$ & \\
\hline 21 D.McM. & $11.6-9.7=-1.9$ & $13.5 \rightleftharpoons 12.6=-0.9$ & \\
\hline 22 R.H. & & $11.9 \rightleftharpoons 9 \cdot 7=-2.2$ & \\
\hline 23 A.H. & $10 \cdot 3-9 \cdot 0=-1 \cdot 3$ & $10.6 \rightleftharpoons 9.0=-1.6$ & \\
\hline 27 R.S. & $13.7-11.8=-1.9(\mathrm{OD})$ & $12.3 \rightleftharpoons 13.1=+0.8(\mathrm{OS})$ & 120 \\
\hline 28 C.S. & $12 \cdot 2-10 \cdot 7=-1.5$ & $15 \cdot 3 \rightleftharpoons 12.9=-2.4$ & \\
\hline $\begin{array}{l}32 \text { M.C. } \\
33 \text { L.H. }\end{array}$ & & $\begin{array}{l}11.6 \rightleftharpoons 10.6=-1.0 \\
13.2 \rightleftharpoons 10.7=-2.5\end{array}$ & \\
\hline & $13 \cdot 3-11 \cdot 2=-2 \cdot 1$ & $13 \cdot 2 \rightleftharpoons 10 \cdot 7=-2 \cdot 5$ & \\
\hline
\end{tabular}

OD $=$ R. eye. $\mathrm{OS}=\mathbf{L}$. eye. 

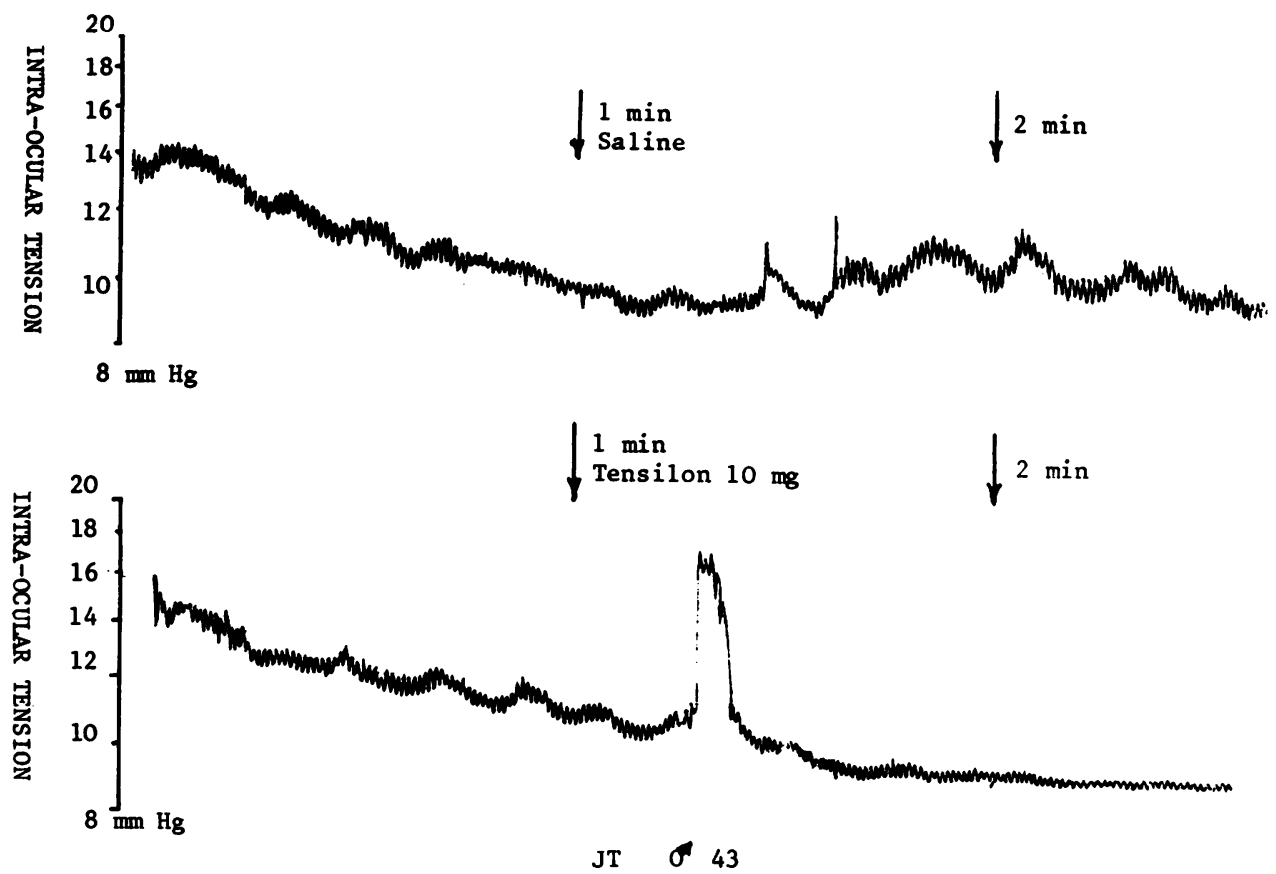

FIG. 4. Record of Tensilon tonography in a myasthenic patient. Top record shows intraocular pressure tracing and the first arrow indicates injection of saline. Bottom record shows intraocular pressure tracing and the first arrow indicates injection of Tensilon.

had been injected $(P>0 \cdot 5)$. In contrast to this there was a significant difference in the myasthenic group of patients between the recordings obtained after saline injection and Tensilon injection $(P<0.01)$. In only one patient was there a complete failure of response. This young woman (N.Co), the most severely affected patient under our care, had almost total, fixed ophthalmoplegia of long standing due to presumed irreversible myopathic change. She had severe bulbar involvement requiring a tracheostomy and it was impossible to perform the studies more than four hours after anticholinesterase (Mestinon) therapy. She obtained slight improvement in her ptosis with the Tensilon during tonography. In one other patient (L.S.) with some fixed ocular muscle weakness, a poor response to Tensilon was seen which did not rise above the initial tension at one minute. A fall of $2.2 \mathrm{~mm} \mathrm{Hg}$ tension was seen over the same period in the other eye after the control injection of normal saline. This patient was also studied within four hours of treatment at which time she was showing evidence of bulbar distress, and hence the response could conceivably have been greater. In one patient (W.P.), with extraocular muscle weakness only, a markedly dissimilar response from each of the two eyes was obtained to Tensilon The intraocular pressure failed to rise above the initial recording in the right eye, although a small response was clearly seen, but increased by $2 \cdot 1 \mathrm{~mm}$ $\mathrm{Hg}$ in the clinically weaker left eye.

Although the absolute levels of intraocular pressure in individual eyes may vary from time to time, the change in intraocular pressure after intravenous injection of both normal saline and Tensilon was shown to be highly reproducible (C.McG. and E.J.). These duplicated records on a myasthenic patient and in a control subject were obtained at intervals of several months. The maximum rise in intraocular pressure observed after Tensilon was $5.0 \mathrm{~mm} \mathrm{Hg}$ (Fig. 4), but this was extremely transient lasting a few seconds only. This patient (J.T.) also had a totally unexplained small rise following normal saline. His extraocular muscular weakness was responsive to Mestinon therapy at that time.

\section{DISCUSSION}

Edrophonium chloride (Tensilon), an analogue of neostigmine, is a rapidly acting, short-lived anticholinesterase agent. In patients with myasthenia 
gravis it produces a temporary increase in muscle strength within one-half to five minutes of intravenous infusion (Osserman and Kaplan, 1952; Osserman and Teng, 1956). When the muscular weakness is clinically confined to the extraocular muscles, the response to Tensilon may be difficult to evaluate, especially in the absence of lid weakness (ptosis). Objective tests involving electromyography of the extraocular muscles (Breinin, 1957) are uncomfortable at best and also produce difficulties in interpretation. The need for a reliable, painless, objective test was apparent and the methods of electronystagmography (ENG) or tonography, utilizing the beneficial response to Tensilon in myasthenia, appeared to offer reasonable possibilities as diagnostic tests.

Theoretically the ENG technique of studying the repetitive contraction of the extraocular muscles induced by optokinetic nystagmus (Blomberg and Persson, 1965) appeared both simple and straightforward. By recording the corneoretinal potential, with its almost linear relationship of amplitude to the angle of gaze (Aschan et al., 1956) it seemed possible to study the size and rate of muscle response on repetitive action. However, although some excellent examples of neuromuscular fatigue with the progressive decline in amplitude of gaze and rate of nystagmus were obtained, the records proved too variable in response, even among healthy controls, to be of value quantitatively. When the latter records were obtained it was impossible to evaluate the beneficial effects of anticholinesterase agents. In their preliminary report on three myasthenic patients, Blomberg and Persson (1965) reported an increase in frequency and amplitude of the nystagmus five minutes after intravenous injection of $10 \mathrm{mg}$ Tensilon. It is not clear why they chose this interval, as most of the effect of Tensilon has disappeared by this time. We are unaware of further reports from these or other workers. In the study reported here clear objective responses were seen in $50 \%$ of myasthenic patients only, whereas a higher proportion showed a variable subjective response.

The intraocular pressure is a function of the formation and outflow of aqueous humour. The pressure is balanced by the rigidity of the sclera and the surrounding extraocular muscles and orbital contents. Transient pressure changes are produced synchronously with the cardiac and respiratory cycles but more lasting effects may be induced by arterial or venous changes (Davson, 1960). Numerous studies have shown that contraction of the extraocular muscles increases the intraocular pressure and that the pressure rise is proportional to the degree of muscle tension (see von Hippel and Grünhagen, 1868, cited by Greaves and Perkins, 1953; Korn- blueth, Jampolsky, Tamler, and Marg, 1966; Collins, Bach-y-Rita, and Loeb, 1967). Kornblueth et al. (1966) found that Tensilon, which increased the activity of the oculorotary muscles only in patients with myasthenia gravis, produced a moderate rise in intraocular pressure after 20 to 30 seconds, coinciding with the increased tonus of the oculorotary muscles. They also showed that the intraocular pressure fell towards the baseline earlier than the decrease in electrical activity of the muscles, presumably because of increased expression of aqueous humor through the outflow channels. Collins and his co-workers (1967) in experimental studies on the rise in intraocular pressure with intravenous administration of graded doses of succinylcholine, showed that section of the orbicularis oculi muscle produced no decrease in the intraocular pressure response. However, surgical removal of the oculorotary muscles, with the smooth muscles remaining intact, completely eliminated the rise in intraocular pressure due to succinylcholine.

An estimate of the intraocular pressure in man may be performed continuously over a four-minute period by an impression tonometer of Schiotz linked to an electronic recorder. The method measures the extent to which a weighted plunger indents the cornea and gives a stable pressure decay curve. The true intraocular pressure may be calculated by adequate calibration (after Friedenwald). In our studies we found that on average the pressure fell by 1.6 to $1.8 \mathrm{~mm} \mathrm{Hg}$ over one minute in the control studies but increased by $1.6 \mathrm{~mm} \mathrm{Hg}$ in myasthenic patients after Tensilon. Similar orders of rise in intraocular pressure were recorded by Kornblueth et al. (1966) and Glaser et al. (1966). The latter authors found that out of 24 studies on myasthenic patients, three eyes failed to show a positive response to Tensilon, although the opposite eye responded in every case. A complete failure of response was seen in only one of the patients in the present series, and a very poor response occurred in another. Both these patients had severe permanent extraocular muscle weakness, and, although we were not able to withdraw all medication in these cases, it appears likely that the intraocular pressure in patients with myasthenia gravis may fail to respond to Tensilon when severe myopathic changes are found.

A false positive rise in intraocular pressure after Tensilon has not previously been reported. We are unable to explain the isolated finding of a small rise in tension in a patient with a sympathetic nerve lesion. Stimulation of the peripheral end of the cut cervical sympathetic nerve leads to a fall in the intraocular pressure (Davson and Matchett, 1951; Greaves and Perkins, 1953), but in some animals the fall may be masked by the contraction of the smooth 
muscle of the orbit and in the rabbit a rise in tension has been reported (Collins, 1967). Whether a sympathectomized eye might be abnormally sensitive to a cholinergic drug is unknown but this possibility warrants further study.

The Tensilon tonography test would appear to be a very useful diagnostic tool in myasthenia gravis limited to the ocular muscles. The absence of response in patients with other ocular neuromuscular diseases also makes it a useful test in the exclusion of myasthenia as a cause of obscure isolated oculorotary muscle weakness. We are unable, however, to recommend the ENG as a diagnostic test as the response which we found was too variable to be assessed quantitatively. Our results with the ENG after Tensilon injection did not appear to show any advantage over simple subjective evaluation.

\section{REFERENCES}

Aschan, G., Bergstedt, M., and Stahle, J. (1956). Nystagmography: recording of nystagmus in clinical neurootological examinations. Acta oto-laryng. (Stockh.), Suppl. No. 129.

Blomberg, L. H., and Persson, T. (1965). A new test for myasthenia gravis-preliminary report. Acta neurol. scand., 41, Suppl. No. 13, 363-364.

Breinin, G. M. (1957). Electromyography-a tool in ocular and neurologic diagnosis. Arch. Ophthal., 57, 161-164.

Collins, C. C. (1967). Evoked pressure responses in the rabbit eye. Science, 155, 106-108.
Collins, C. C., Bach-y-Rita, P., and Loeb, D. R. (1967). Intraocular pressure variation with oculorotary muscle tension. Amer. J. Physiol., 213, 1039-1043.

Davson, H. (1960). Intracranial and intraocular fluids. Handbook of Physiology, Neurophysiology. Edited by J. Field. Washington D.C. Amer. Physiol. Soc., 1960, sect. 1. Vol. III, p. 1761-1788.

Davson, H., and Matchett, P. A. (1951). The control of the intra-ocular pressure in the rabbit. J. Physiol.(Lond.), 113, 387-397.

Glaser, J. S., Miller, G. R., and Gass, J. D. M. (1966). The edrophonium tonogram test in myasthenia gravis. Arch. Ophthal., 76, 368-373.

Greaves, D. P., and Perkins, E. S. (1953). Influence of the third cranial nerve on intra-ocular pressure. Brit.J. Ophthal., 37, 54-57.

Von Hippel, A., and Grünhagen, A. (1868). Über den Einfluss der Nerven auf die Höhe des intraocularen Druckes. Albrecht v. Graefes Arch. Ophthal., 14, 219-258.

Kornblueth, W., Jampolsky, A., Tamler, E., and Marg, E. (1960). Contraction of the oculorotary muscles and $\overrightarrow{0}$ intraocular pressure. A tonographic and electromyographic study of the effect of edrophonium chloride (Tensilon) and succinylcholine (Anectine) on the intraocular pressure. Amer. J. Ophtha!., 49, 1381-1387.

Osserman, K. E., and Kaplan, L. I. (1952). Rapid diagnostic test for myasthenia gravis. Increased muscle strength, $\omega$ without fasciculations, after intravenous administra- $v$ tion of edrophonium (Tensilon) chloride. J. Amer med. Ass., 150, 265-268.

Osserman, K. E., and Teng, P. (1956). Studies in myastheni gravis. A rapid diagnostic test. Further progress wite edrophonium (Tensilon) chloride. J. Amer. med. Ass 160, 153-155.

Schott, E. (1922). Ưber die Registrierung des Nystagmus une anderer Augenbewgungen vermittels des Saiten galvanometers. Disch. Arch. klin. Med., 140, 79-90. 